\title{
Protein-protein interaction of Rv0148 with Htdy and its predicted role towards drug resistance in Mycobacterium tuberculosis
}

\author{
Gunapati Bhargavi ${ }^{1}$, Sameer Hassan², Subramanyam Balaji', Srikanth Prasad Tripathy ${ }^{1}$ and Kannan Palaniyandi ${ }^{{ }^{*}}$
}

\begin{abstract}
Background: Mycobacterium tuberculosis resides inside host macrophages during infection and adapts to resilient stresses generated by the host immune system. As a response, M. tuberculosis codes for short-chain dehydrogenases/ reductases (SDRs). These SDRs are nicotinamide adenine dinucleotide-reliant oxidoreductases involved in cell homeostasis. The precise function of oxidoreductases in bacteria especially M. tuberculosis were not fully explored. This study aimed to know the detail functional role of one of the oxidoreductase Rv0148 in M. tuberculosis.

Results: In silico analysis revealed that Rv0148 interacts with Htdy (Rv3389) and the protein interactions were confirmed using far western blot. Gene knockout mutant of Rv0148 in M. tuberculosis was constructed by specialized transduction. Macrophage cell line infection with this knockout mutant showed increased expression of pro-inflammatory cytokines. This knockout mutant is sensitive to oxidative, nitrogen, redox and electron transport inhibitor stress agents. Drug susceptibility testing of the deletion mutant showed resistance to first-line drugs such as streptomycin and ethambutol and second-line aminoglycosides such as amikacin and kanamycin. Based on interactorme analysis for Rv0148 using STRING database, we identified 220 most probable interacting partners for Htdy protein. In the Rv0148 knockout mutants, high expression of htdy was observed and we hypothesize that this would have perturbed the interactome thus resulting in drug resistance. Finally, we propose that Rv0148 and Htdy are functionally interconnected and involved in drug resistance and cell homeostasis of M. tuberculosis.
\end{abstract}

Conclusions: Our study suggests that Rv0148 plays a significant role in various functional aspects such as intermediatory metabolism, stress, homeostasis and also in drug resistance.

Keywords: Mycobacterium tuberculosis, Tuberculosis, Oxidoreductases, Rv0148, Htdy, Drug resistance, Stress response

\section{Background}

Tuberculosis (TB) remains one of the world's leading cause of death every year among infectious diseases [1]. In 2018, WHO reported that 10.4 million new cases and 1.8 million deaths occur worldwide each year [2]. With the increase in multidrug and extensive drug-resistance TB, there is a need to develop newer diagnostics and vaccines [3]. It is well known that Mycobacterium tuberculosis spreads through

\footnotetext{
* Correspondence: kannanvet@rediffmail.com

'Department of Immunology, ICMR-National Institute for Research in Tuberculosis, \#1, Mayor Sathyamoorthy Road, Chetpet, Chennai 600031, India Full list of author information is available at the end of the article
}

aerosol, survives in oxygen and nutrition depleted environments and persists for long periods in the host cells [4-6]. The change in the host metabolism is thereby continuously monitored by $M$. tuberculosis to perform its active replication and persistence $[7,8]$. M. tuberculosis during infection is exposed to various anti-bacterial agents secreted by macrophages. In addition, macrophages produce reactive oxygen species (ROS) and reactive nitrogen species (RNS) [9, 10]. The ROS interact directly and the resulting super oxides are converted into various oxidants like hypochlorite $(\mathrm{HClO})$, peroxides $\left(\mathrm{H}_{2} \mathrm{O}_{2}\right)$, peroxynitrite $\left(\mathrm{ONOO}^{-}\right)$and hydroxy radicals, which damage the bacterial cells [11]. The bacterial cells

\section{$\triangle B M C$}

(c) The Author(s). 2020 Open Access This article is licensed under a Creative Commons Attribution 4.0 International License, which permits use, sharing, adaptation, distribution and reproduction in any medium or format, as long as you give appropriate credit to the original author(s) and the source, provide a link to the Creative Commons licence, and indicate if changes were made. The images or other third party material in this article are included in the article's Creative Commons licence, unless indicated otherwise in a credit line to the material. If material is not included in the article's Creative Commons licence and your intended use is not permitted by statutory regulation or exceeds the permitted use, you will need to obtain permission directly from the copyright holder. To view a copy of this licence, visit http://creativecommons.org/licenses/by/4.0/ The Creative Commons Public Domain Dedication waiver (http://creativecommons.org/publicdomain/zero/1.0/) applies to the data made available in this article, unless otherwise stated in a credit line to the data. 
resist stress using in-built mechanism. M. tuberculosis uses various defence mechanisms to damage the cell. $O x y R$ and sox $R$ are two prokaryotic regulators against peroxides and superoxides. Due to the absence of oxyR in $M$. tuberculosis, peroxidase stress is managed by alkylhydroperoxidase reductase (AhpC) by detoxifying the peroxides [12]. In addition, other peroxidases such as KatG, superoxide dismutase, peroxiredoxin (AhpE) and thioredoxin reductase (Tpx) help in reducing peroxidase activity and also in controlling the oxidative and nitrosative stress conditions [13-15]. Though the components involved in the oxidative stress of $M$. tuberculosis have been identified, the functional importance remains unclear. Gene interaction and knockout studies thoroughly predict the functional interconnection between the genes and their role in the metabolism of bacteria.

In this study, for the first time, we attempted to predict the functional role of one of the hypothetical oxidoreductase Rv0148 of M. tuberculosis. Rv0148 is a hypothetical protein/ putative short-chain dehydrogenase/reductase (SDR) and exhibits $100 \%$ similarity to $M$. bovis and M. africanum and $87 \%$ to M. avium [16]. Rv0148 possesses the conserved SDR domain. As aminoglycosides bind to SDR sites, Rv0148 might neutralize the overexpression of aminoglycosides [17]. Earlier studies reported that over expression of $M$. tuberculosis Rv0148 from multidrug-resistance isolates in Escherichia coli showed two- to three-folds of higher shift in MIC [18]. Previous studies from our lab identified that PknI, one of the 11 serine-threonine protein kinases (STPKs), interacts with two proteins Rv2159c and Rv0148 [19]. Rv2159c was characterized using gene knockdown studies, and its interaction with $\mathrm{PknI}$ increased its peroxidase activity several folds in the mutant strain [20].

As an extension to the previous study we have chosen Rv0148. It was characterized through bioinformatics tools using sequence and protein interaction analyses. In sequence analysis using Pfam database, we found Rv0148 carrying well-conserved nicotinamide adenine dinucleotide (NAD) domain, whereas other homologues possessed MaoC domain along with SDR. Furthermore, by in silico approach we identified that Rv0148 mainly interacts with hydroxyl acyl thioester dehydratase Htdy, a protein interaction which was confirmed by far western blotting (WB) and pull-down assay. We have constructed the gene knock out mutant of Rv0148 $(\Delta 0148)$ by specialized transduction to understand the functional role of the gene. In vivo studies confirmed that this mutant induces pro-inflammatory cytokines and is susceptible to oxidative and nitrogen stress compounds. $\Delta 0148$ confers drug resistance to streptomycin, ethambutol, amikacin and kanamycin. This might be due to modified functional network in the absence of Rv0148. Overall, the study suggested that Rv0148, though a non-essential gene, is functionally involved in drug resistance and is interconnected with other drug-resistance genes. The absence of Rv0148 displays its prominent role in host immunity.

\section{Results \\ Sequence homologues of Rv0148}

To identify the sequence homologues of Rv0148 in other organisms, blast search was performed against the nonreductant database in NCBI; 104 sequence homologues were selected and the sequences were reconfirmed based on short dehydrogenase domain in these sequences. Most of these sequences had the short dehydrogenase with a few sequences having both short dehydrogenase and MaoC dehydratase domain. A HMM profile based analysis (https://www.ebi.ac.uk/Tools/hmmer/search/hmmsearch) using the adh short domain profile from Pfam database identified 1270 significant sequences from Swissprot database (Table S1). Further, we searched the MaoC dehydratase sequence against mycobacterial genome and identified Htdy protein. Based on the analysis, we identified Rv0148 has only SDR. We searched for Rv0148 in STRING database and identified that Rv0148 interacts with Htdy protein (Fig. 1a). And this formed the basis for the subsequent analysis to predict the interaction of Rv0148 with Hdty using bioinformatics tools and then to validate the interaction using experimental methods.

\section{Homology modelling of Rv0148}

Because the structure of Rv0148 was not determined by experimental methods, we attempted to predict its 3D structure using the homology modelling approach. From the blast search results against PDB for a suitable template in complex with NAD, it was observed that Rv0148 showed the best alignment with human 17-betahydroxysteroid dehydrogenase type 4 in complex with NAD (PDB code 1ZBQ) and was chosen as the template. The sequence coverage between Rv0148 and $1 \mathrm{ZBQ}$ was $95 \%$ with a sequence identity of $52 \%, E$-value of 2e-96) and gap of $2 \%$. Both Rv0148 and 1ZBQ have short-chain dehydrogenase domain (PF00106). The 3D structure of Rv0148 was modelled (Fig. 2a) using the model-default python script in MODELLER software and the sequence alignment used for predicting the model structure is shown in Fig. 1b. The predicted model was validated using PROCHECK, profile-3D, and ProSA-web. Stereochemical properties of the predicted model were evaluated using PROCHECK to analyse the Ramachandran plot (Fig. 2b).

The plot revealed that the occurrence of $92.3 \%$ amino acids was in the favoured region, $7.3 \%$ in the generously allowed region and $0.4 \%$ in the disallowed region. $Z$ score was -7.89 for the model structure determined using ProSA-web, a program used for validating protein structure, and was located within the space determined by X-ray crystallography (Fig. 2c). Thus, the overall 


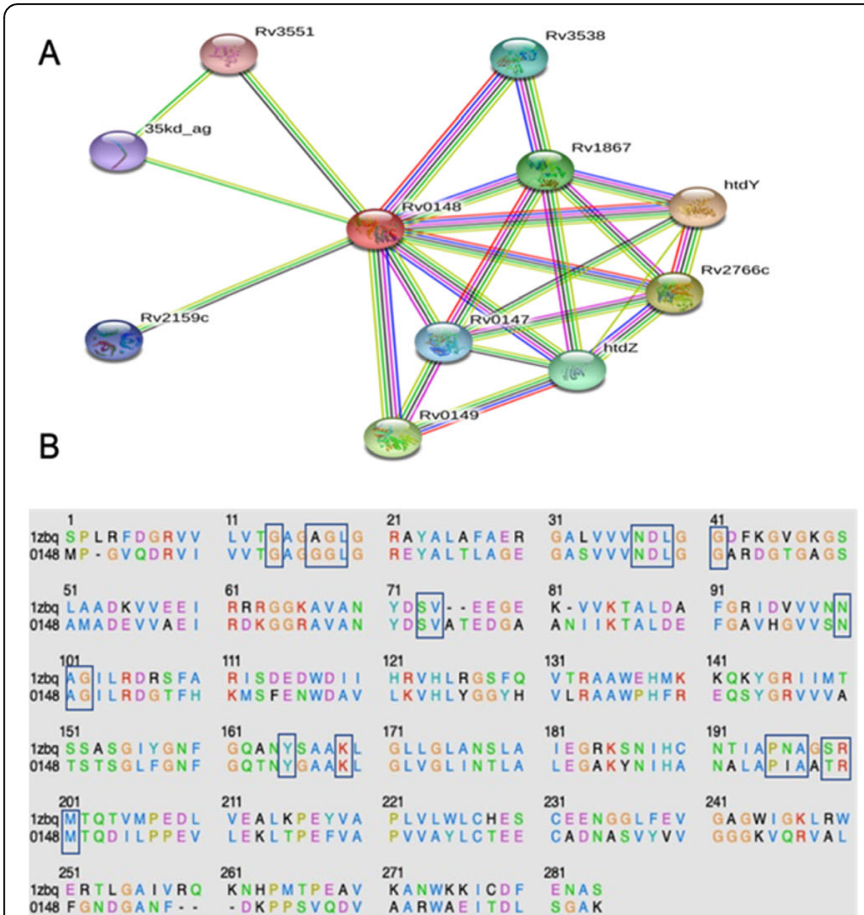

\section{C}

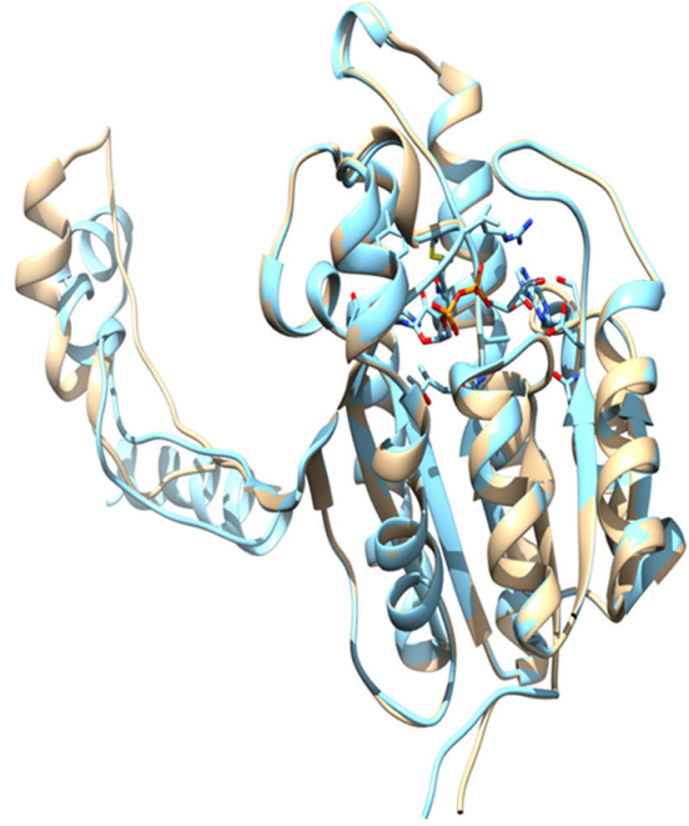

Fig. 1 a Protein-protein interaction from the STRING database for Rv0148 protein. b Sequence comparison of Rv0148 with a template sequence (1ZBQ). The black boxes are the mapping binding sites for Rv0148 based on the template sequence. $\mathbf{c}$ The structural superimposition between nicotinamide adenine dinucleotide (NAD)-docked RV0148 (brown) and template, 1ZBQ (cyan). The NAD is represented in stick form

results from structural superimposition, Ramachandran plot, verify-3D, and ProSA-web reveal that the predicted model is satisfactory and thus considered for further analysis. Profile-3D of the Rv1048 model was 90.36, thus suggesting that $90.36 \%$ of the residues have an average 3D-1D score $\geq 2$ (Fig. 2d).

\section{Docking of NAD within the active site of Rv0148}

The docking of NAD co-factor was performed using GOLD software. However, a primary docking of the bound NAD to the template structure $1 \mathrm{ZBQ}$ was redocked in its binding site to evaluate the docking process. The RMSD of the resulting docking of NAD to $1 Z B Q$ was $0.86 \AA$, suggesting that the docking program is able to reproduce a structure very close to the experimental structure. In order to discover the putative binding pose of NAD co-factor in Rv0148, the binding site for Rv0148 was mapped based on 1ZBQ (Fig. 1b). The best-predicted pose of NAD within the active site of Rv0148 had a score of $95.44 \AA$ (Fig. 1c).

\section{Rv0148 and Htdy interaction analysis}

The crystallographically determined structure of Htdy (PDB code 3KHP) and the predicted model structure of Rv0148 were used for docking using the ClusPro server. The structure from the largest cluster and with the lowest energy was selected and examined for the interaction between the two complexes (Fig. 3a). The residues interacting between the two proteins Rv0148 and Htdy from the docked complex were then mapped to identify the active site (Fig. 3b).

\section{Cloning, expression and purification of Rv0148 and Htdy}

The coding region of the two genes was amplified by PCR and the product matches the size of Rv0148 with $858 \mathrm{bp}$ and $h t d y$ with $969 \mathrm{bp}$. The E. coli strain (BL21) expressed pGBRJ3 Htdy as His-tagged protein and pGBRJ2 0148 as GST-tagged protein (Fig. S1). The protein was purified. The mass of Htdy is $31 \mathrm{kDa}$ and Rv0148 GST is $55 \mathrm{kDa}$. These correspond to the expected mass of the above proteins through western blot.

\section{Interaction of Rv0148 and Htdy}

The pull-down assay with recombinant His-Htdy (PGBRJ3) lysate using Ni-NTA affinity chromatography confirmed that the Htdy was able to pull down GSTtagged Rv0148 (PGBRJ2). Simultaneously, the GSTtagged lysate was able to pull down His tag recombinant Htdy (Fig. 4). The pull-down assay and far western blot confirmed that Rv0148 interacts with Htdy protein.

\section{Generation of $\Delta 0148$ knockout mutant in $M$. tuberculosis}

We constructed knockout mutant of $M$. tuberculosis for not expressing Rv0148 by phage-facilitated allelic exchange [21]. The coding region of the gene was replaced by the 
A

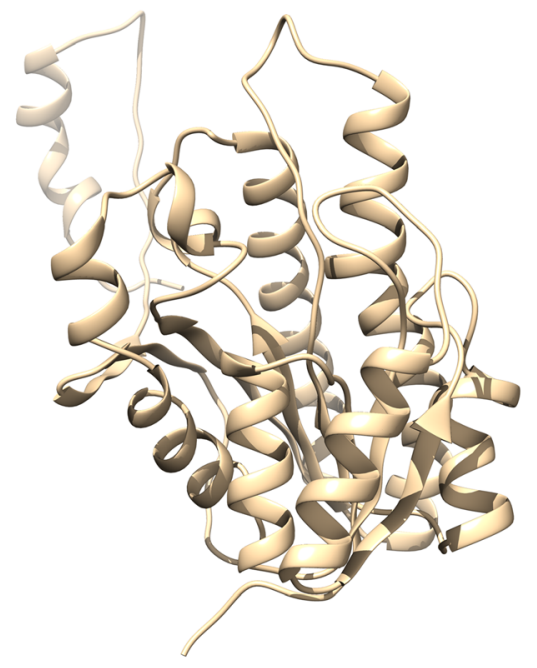

C

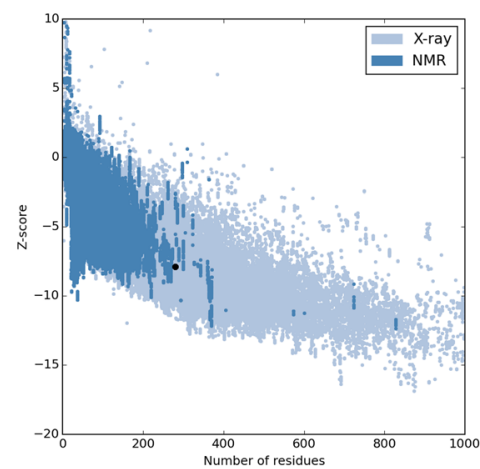

B

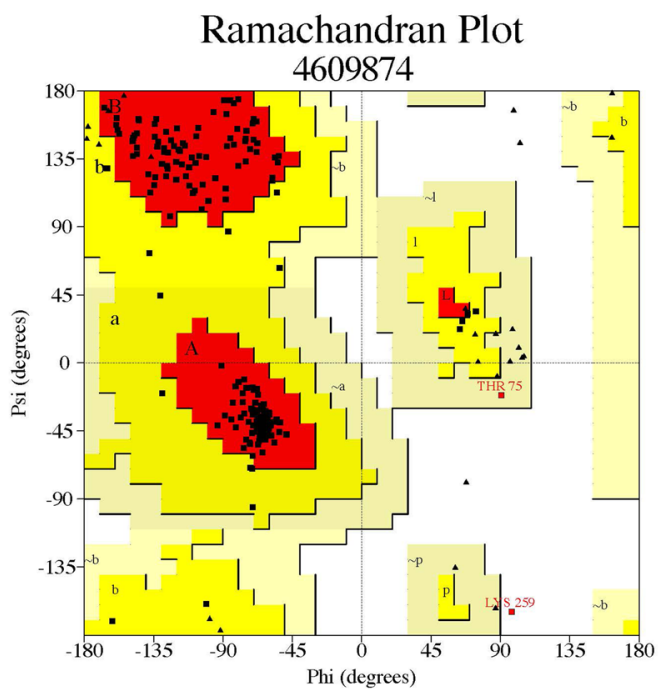

D

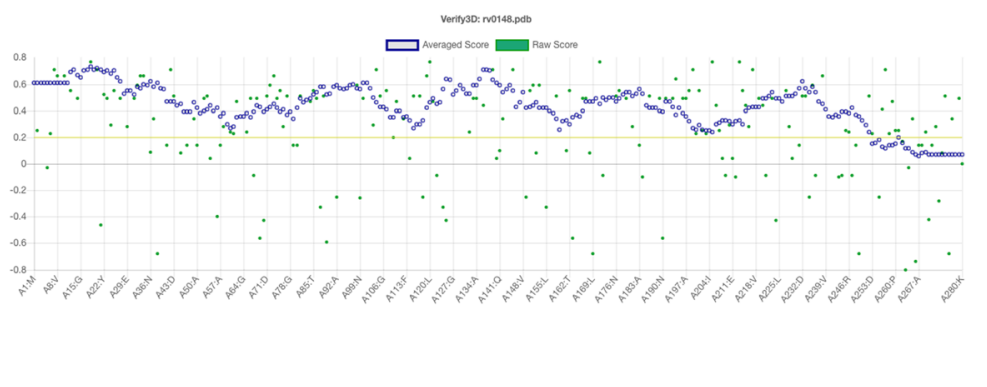

Fig. 2 a Predicted 3D structure of Rv0148. b Ramachandran plot for the predicted model structure of Rv0148. c Plot showing residue energy with Z-score for the Rv0148 model. The blue and grey colours represent the experimentally determined structures using NMR and X-ray, respectively. The Z-score for Rv0148 model falls within the range of the experimentally determined structures. $\mathbf{d}$ Plot showing the average 3D-1D score for every residue of the model structure

hygromycin cassette and four fragments were generated with 3.6, 1.6, 0.837 and 0.605 bp product sizes (Fig. S1). The $50 \mathrm{~kb}$ phAE159 shuttle phasmid with AES retains $6.642 \mathrm{~kb}$ (Fig. $\mathrm{S} 2)$. The generated high-titre transducing phages were used for specialized transduction and the knockout mutant was generated successfully and named as $\Delta 0148$ (Fig. 5). We confirmed the knockout mutant using sequencing, PCR for hygromycin cassette and also through real-time PCR (RTPCR) using gene-specific primers (Table S3).

\section{Colony morphology and growth kinetics}

Gene disruption shows no distinct effect in the cell development of the knockout strain compared to $\mathrm{H}_{37} \mathrm{Rv}$. To elucidate if the knockout of Rv0148 confers any change in vitro, we compared the growth kinetics of
$\mathrm{H}_{37} \mathrm{Rv}, \Delta 0148$ and $\mathrm{C} \Delta 0148$ in $7 \mathrm{H} 9$-enriched media. All the strains showed similar growth and there was no distinct difference observed in in vitro survival of $\Delta 0148$.

\section{Cytokines analysis using ELISA}

The cell-free supernatants after post-infection were analysed for the expression of pro-inflammatory cytokines IL-1 $\beta$, IL- 6 and TNF- $\alpha$ and anti-inflammatory cytokines IL-10, IL-12p40, IL-12p70 and IL-4. Enhanced expression of IL-1 $\beta$, IL- 6 and TNF- $\alpha$ cytokines was observed in $\Delta 0148$ infected with THP-1 macrophages (Fig. 6a-c). Similarly, reduced level of expression of IL-10, IL-12p40, IL-12p70 and IL- 4 was observed in $\Delta 0148$ compared to wild-type $\mathrm{H}_{37} \mathrm{Rv}$ (data not shown). The expression was analysed using appropriate statistical methods. 


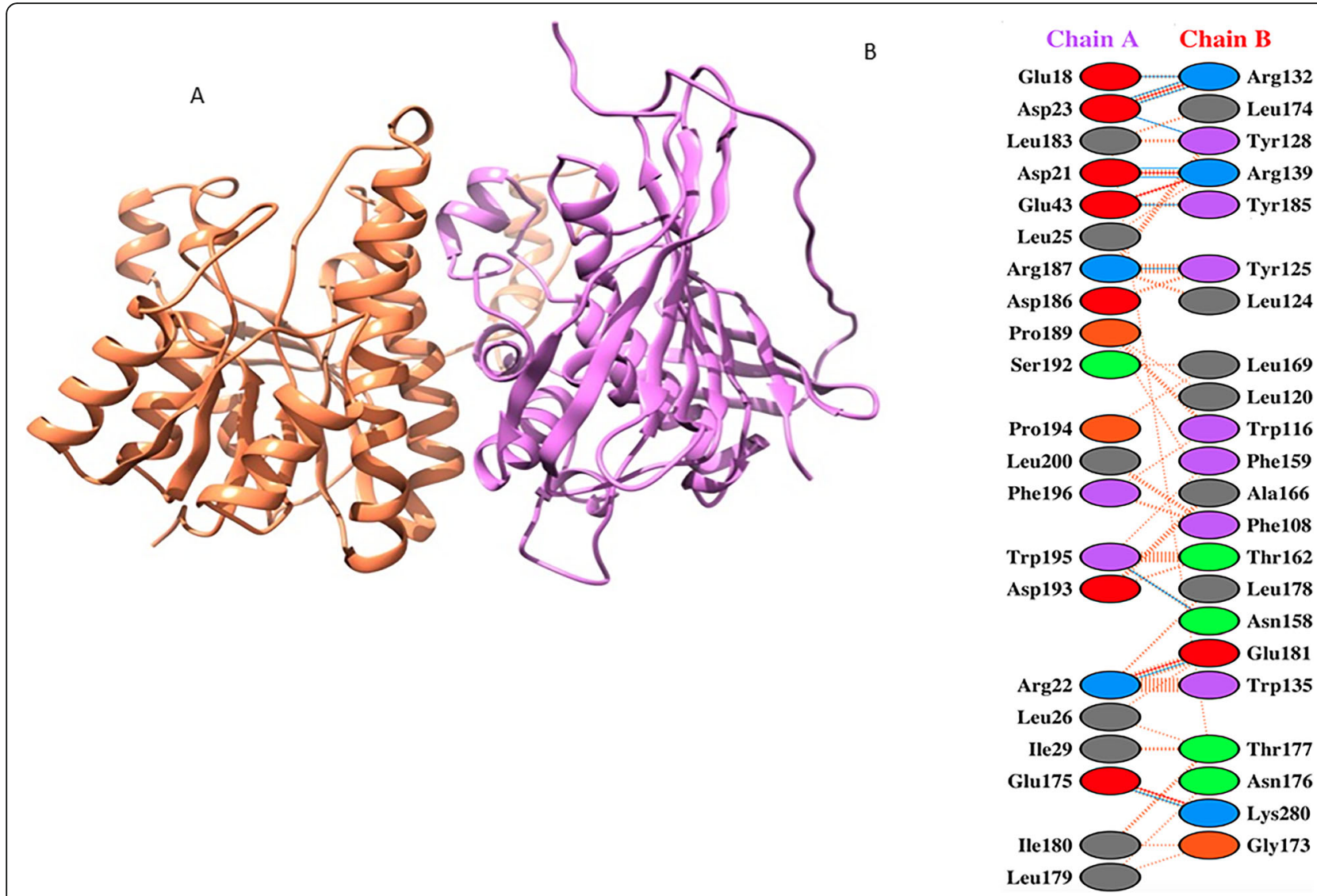

Fig. 3 a The predicted interaction of Rv0148 (orange) and Htdy (purple) protein structures using ClusPro protein-protein interaction server. b The figure showing interacting residues between the two proteins. Chain A \& B, chain A represents Htdy and chain B represents Rv0148

\section{Effect on inhibition of the electron transport chain in $\Delta 0148$}

Rv0148 is predicted to be involved in the intermediatory metabolism of $M$. tuberculosis. The ETC plays an important role in the production of proton motive force (PMF) in the metabolism of bacteria. ETC consists of five complexes I, II, III, IV and V, and inhibition of these complexes could accommodate changes in the growth of bacteria. Rotenone is an inhibitor of complex I whereas oxaloacetate inhibits complex II. It was observed that the exposure of $\Delta 0148$ to $140 \mu \mathrm{M}$ rotenone and $2 \mathrm{mM}$ oxaloacetate significantly decreases the growth (Fig. 7a and b). The result suggests that $\Delta 0148$ strain has a distinct role in the ETC. The significance was reported using statistical tools.

\section{Effect of oxidative and nitrosative stress in $\Delta 0148$}

In diseased patients, mycobacterium resides in the alveolar macrophages in the initial stage of infection and secretes various ROS and RNS. We investigated whether these stresses affect the metabolism of $\Delta 0148$ strain when exposed to $5 \mathrm{mM}$ hydrogen peroxide $\left(\mathrm{H}_{2} \mathrm{O}_{2}\right), 5$ $\mathrm{mM}$ cumene hydroperoxide, $2 \mathrm{mM}$ thiol-reductant DTT and $1 \%$ sulphoxide (DMSO). $\Delta 0148$ is sensitive to oxidative stress components and to nitrogen derivatives and there is decrease in growth of $\Delta 0148$ compared to wildtype $\mathrm{H}_{37} \mathrm{Rv}$ (Fig. $8 \mathrm{a}-\mathrm{d}$ ). It was concluded that the growth of $\Delta 0148$ declined on exposure to ETC, oxidative and nitrosative stress agents. The result was considered using standard statistical methods.

\section{Sensitivity and resistance to first-line and second-line drugs}

BACTEC MGIT was performed with first-line and second-line drugs and shows that $\Delta 0148$ is resistant to streptomycin, ethambutol, amikacin, and kanamycin. $\mathrm{H}_{37} \mathrm{Rv}$ was maintained as a control for all these drug sensitivity assays (Table 1).

\section{Interactomic analysis}

The STITCH database was used to identify M. tuberculosis proteins that interact with three anti-TB drugs streptomycin, kanamycin and amikacin. For each of the proteins interacting to the respective drugs identified from the STITCH database, we collected the interactomes with high confidence $>0.7$ from STRING 

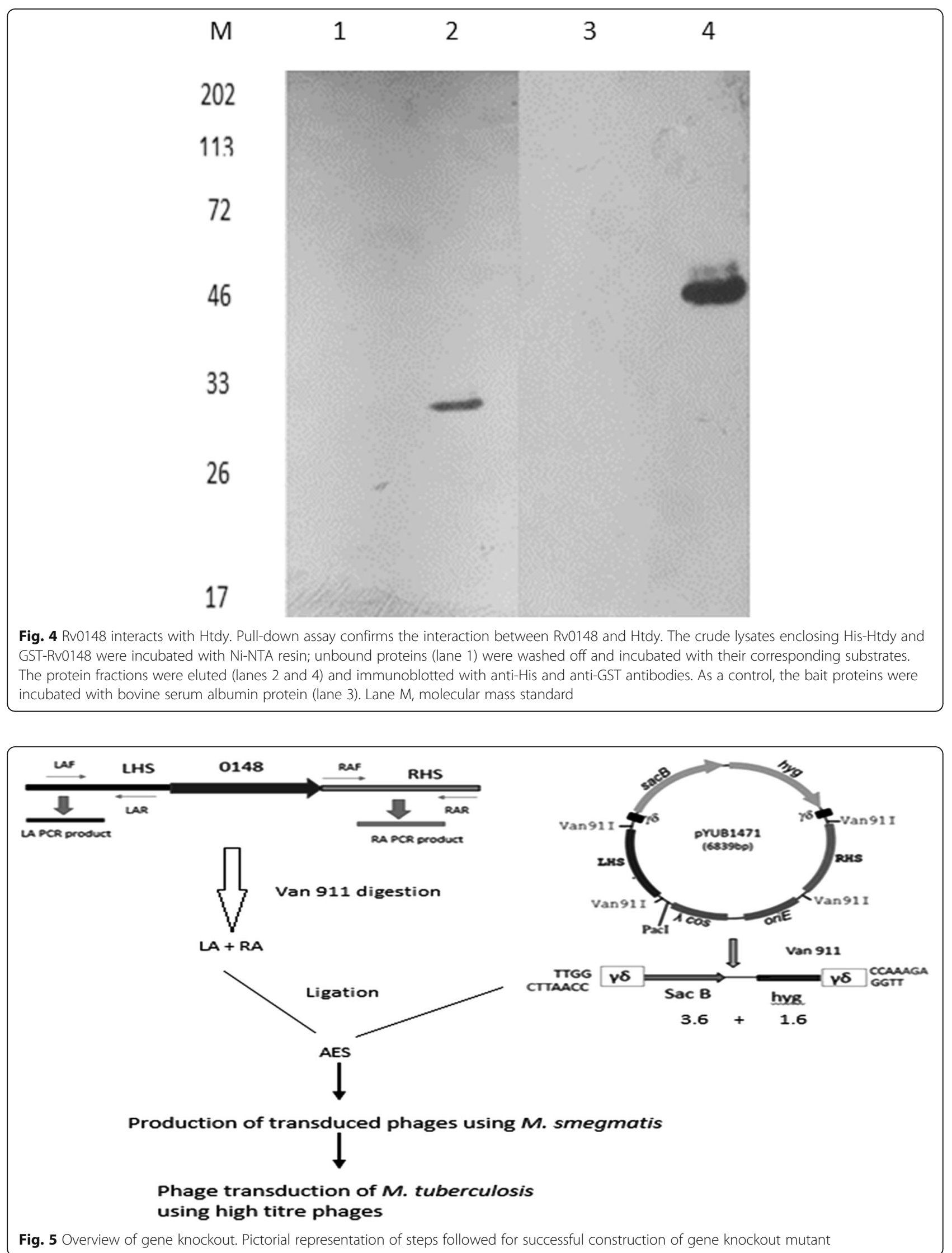


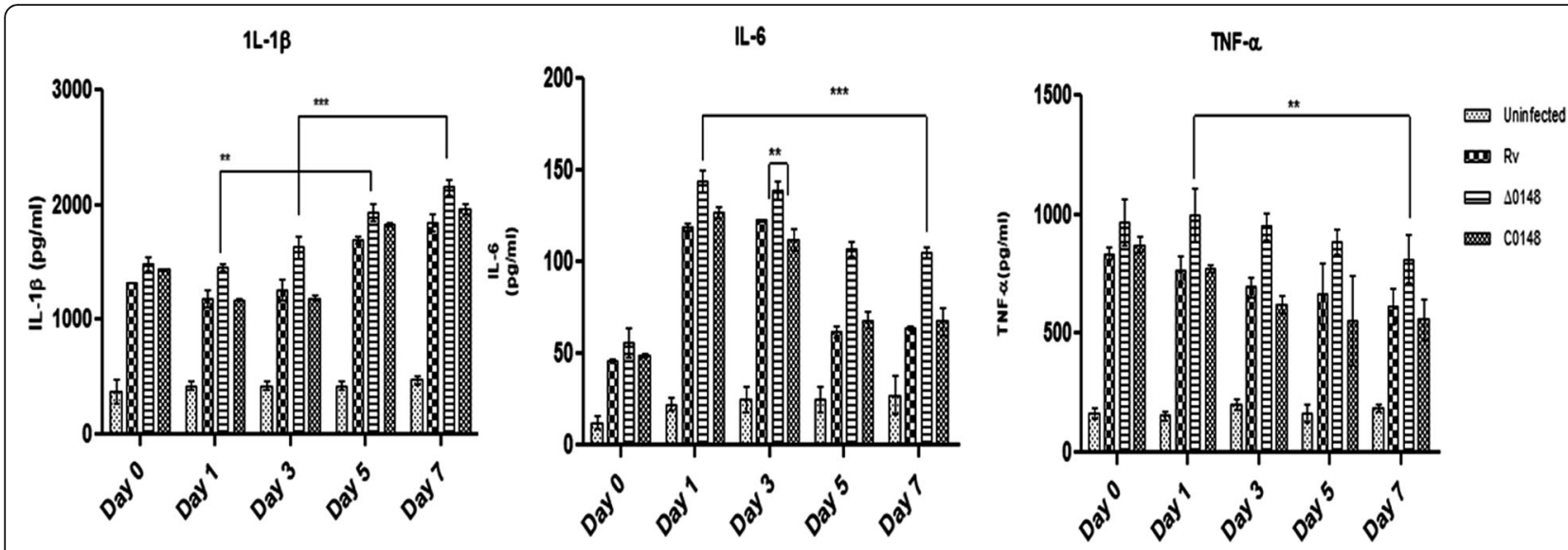

Fig. 6 Cytokines secreted by macrophages infection. $H_{37} R v, \Delta 0148$ and $C \Delta 0148$ strains after post-infection cytokines were measured according to protocol. The capture antibody was coated onto the wells; to samples of $100 \mu \mathrm{L}$ were added detection antibody followed by substrate solution to identify the specific cytokines. IL-1 $\beta$, IL-6 and TNF-a. Two-way ANOVA was performed. The values were taken by considering the average of three triplicate independent experiments. Data represents mean, Standard error mean deviation (SEM) in each experiment and error bars indicate mean \pm standard deviation SD. ${ }^{* *}$ significant at $P<0.001$ and ${ }^{* *}$ significant at $P<0.01$

database to ensure a level of confidence for the interactions. Simultaneously, we collected the highest confidence interactomes for Rv0148, htdy and EIS genes from STRING (Table 2). Finally, we produced an interactome of 220 proteins that connect Rv0148, Htdy and EIS with the proteins that either interact directly or indirectly with the three drugs. The M. tuberculosis PPI (protein-protein interaction) network incorporating all the identified proteins is shown in Fig. 9. Comparing and analysing the intersection of proteins that connect the three drugs kanamycin, amikacin and streptomycin and the three proteins Rv0148, Htdy and EIS resulted in 57 proteins (Fig. S3).
Analysing the 220 genes, except for streptomycin, we identified genes connected to kanamycin and amikacin as an intersection between interacting genes of Rv0148, htdy and EIS.

\section{Differential expression of $h t d y$}

The interactome analysis predicted that $h t d y$ is also involved in drug resistance. Expression of htdy in the $\Delta 0148$ strain of $M$. tuberculosis was analysed using $\mathrm{qPCR}$ as mentioned earlier. The $h t d y$ expression in $\Delta 0148$ increased to 1.25 -fold whereas the wild-type strain showed 0.7-fold (Fig. 10 and Table S4). The fold expression was

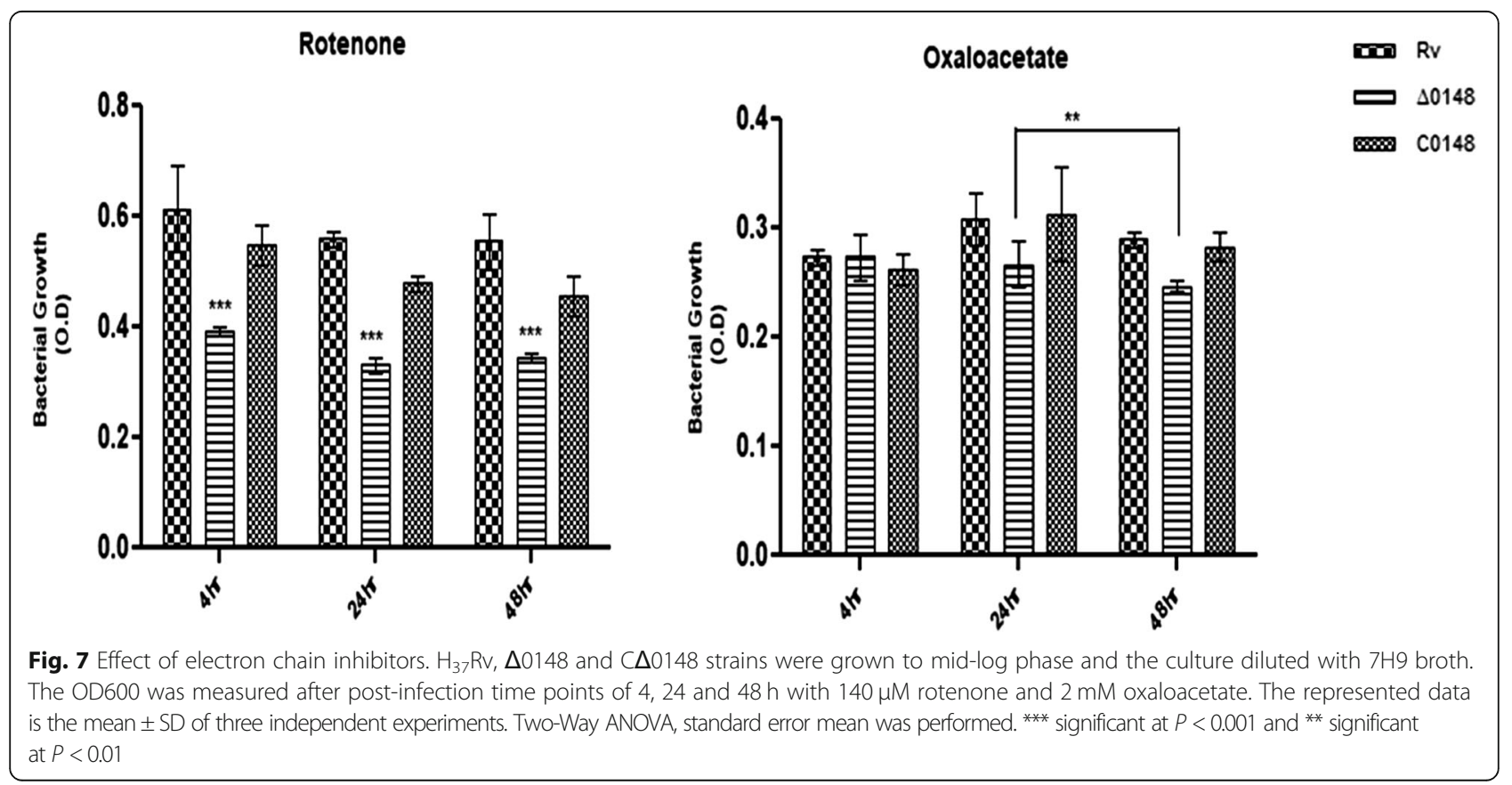



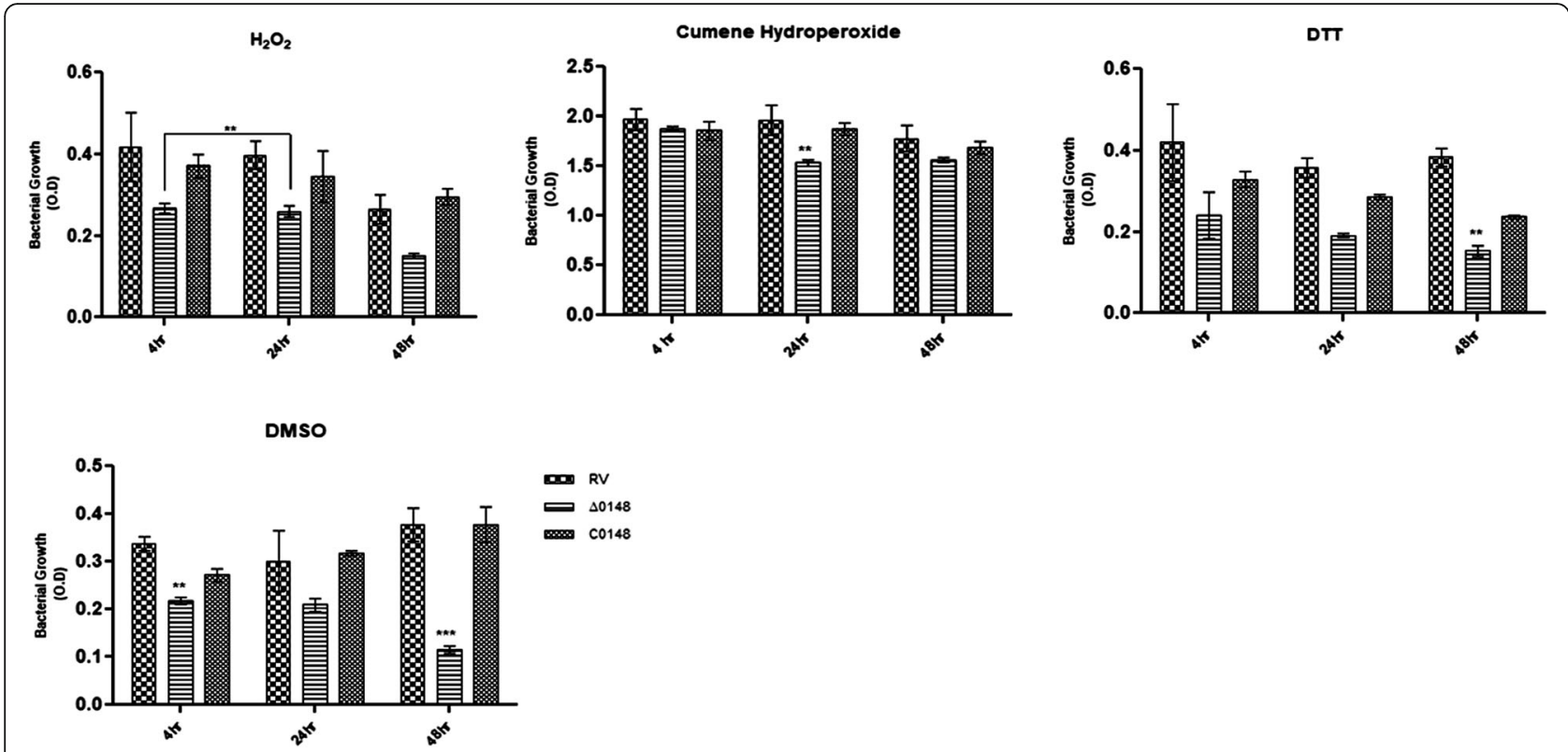

Fig. 8 Effect of stress in $\Delta 0148$. The mid-log phase cultures were subjected to oxidative and nitrogen stress compounds and OD values were measured after post-exposure with $5 \mathrm{mM} \mathrm{H}_{2} \mathrm{O}_{2}, 5 \mathrm{mM}$ cumene hydroperoxide, $2 \mathrm{mM}$ dithiothreitol and 1\% DMSO at 4,24 and $48 \mathrm{~h}$. The values were taken by performing three independent experiments. The bar graphs were plotted by considering the mean, SEM and using Two-Way ANOVA and error bars indicate mean \pm SD. significant at $P<0.001$ and ** significant at $P<0.01$

calculated using SDS 2.4 software and relative quantity (RQ value) method.

\section{Discussion}

In this study, we report the cloning, overexpression, purification, gene knockout and interacting partners of Rv0148, a hypothetical protein that belongs to the oxidoreductase family of $M$. tuberculosis. Through bioinformatics approaches, we concluded that Rv0148 is a NAD oxidoreductase protein with SDR domain. Rv0148 is predicted as interacting with a protein that has an MaoC dehydratase domain and the subsequent blast analysis led to the identification of Htdy protein. Further, the string analysis of Rv0148 displayed 10 interacting partners such as Rv3538, Rv0149, mbtB, fas, fadB, aacA2, Rv0147, Rv2228c, muT1 and htdy thus confirming our analysis. The predicted Htdy as an interacting partner of Rv0148 was further confirmed through far WB and pull-down assays.

We generated gene knockout mutant of Rv0148 in $M$. tuberculosis and show that Rv0148 is a non-essential gene as confirmed in the previous report [22]. $\Delta 0148$ grew similarly as the wild type under constant shaking in enriched 7H9 media. This indicates clearly that the loss of Rv0148 does not lead to any change in the growth of $M$. tuberculosis. There were no correlative morphological changes in cell structure owing to the deletion of Rv0148.

We infected the macrophage cell lines with mutants for cytokine profiling. Increased expression of proinflammatory cytokines predicts that $\Delta 0148$ might be involved in host immune responses [23, 24]. The lower level expression of anti-inflammatory cytokines IL-10, IL-4, IL-12p40 and IL-12p70 indicates that $\Delta 0148$ has no role in inflammation [25].

In aerobic organisms, respiratory chain possesses inner membrane complexes associated with energy production. Complex I known as NADH quinone oxidoreductase transfers electrons from $\mathrm{NADH}$ to quinone associated with proton transfer across the membrane. Complex II is involved in tricarboxylic acid cycle without transfer of protons. Complex III transfers electrons from quinone to cytochrome $c$. Complexes III and IV receive these electrons and transfer them to oxygen. Complex V using PMF synthesizes ATP molecules [26]. Rv0148 is a NAD oxidoreductase involved in the function of

Table 1 Resistance and sensitivity to drugs

\begin{tabular}{llllllll}
\hline Name of sample & Strep $(1 \mu \mathrm{g} / \mathrm{mL})$ & $\mathrm{INH}(0.1 \mu \mathrm{g} / \mathrm{mL})$ & $\mathrm{Eth}(5 \mu \mathrm{g} / \mathrm{mL})$ & $\mathrm{RIF}(1 \mu \mathrm{g} / \mathrm{mlL}$ & $\mathrm{KAN}(2.5 \mu \mathrm{g} / \mathrm{mL})$ & $\mathrm{OFLO}(2 \mu \mathrm{g} / \mathrm{mL})$ & $\mathrm{AMl}(1 \mu \mathrm{g} / \mathrm{mL})$ \\
\hline $\mathrm{H}_{37} \mathrm{RV}$ & $\mathrm{S}$ & $\mathrm{S}$ & $\mathrm{S}$ & $\mathrm{S}$ & $\mathrm{S}$ & $\mathrm{S}$ & $\mathrm{S}$ \\
$\Delta 0148$ & $\mathrm{R}$ & $\mathrm{S}$ & $\mathrm{R}$ & $\mathrm{S}$ & $\mathrm{R}$ & $\mathrm{S}$ & $\mathrm{R}$
\end{tabular}

Abbreviations: $A M I$ amikacin, Eth ethambutol, INH isoniazid, KAN kanamycin, OFLO ofloxacin, $R$ resistance, RIF rifampicin, $S$ sensitive, Strep streptomycin 
Table 2 List of drug-resistance genes interacting with Rv0148

\begin{tabular}{|c|c|c|c|}
\hline Rv0148 vs kanamycin & Rv0148 vs EIS & EIS vs amikacin & Rv0148 vs Htdy \\
\hline & & & fadb \\
\hline \multirow[t]{2}{*}{ Rv3538 } & accA2 & eis & accA2 \\
\hline & Fas & Rv2417c & Rv3538 \\
\hline Fas & kasA & Rv2414c & Rv0148 \\
\hline Htdy & fabD & Rv3055 & fas \\
\hline$H t d x$ & kasB & Rv1312 & acps \\
\hline Rv0130 & AccD3 & Rv1571 & kasA \\
\hline \multirow[t]{27}{*}{ mutT1 } & eis & Rv3605c & Pks13 \\
\hline & & Rv3839 & $\mathrm{mbtB}$ \\
\hline & & Rv0428c & Rv0216 \\
\hline & & Rv0495c & Rv2499c \\
\hline & & Rv2242 & $\mathrm{Htdx}$ \\
\hline & & & hatB \\
\hline & & & fabD \\
\hline & & & Rv0130 \\
\hline & & & Rv3797 \\
\hline & & & FadE9 \\
\hline & & & fadE25 \\
\hline & & & fadE10 \\
\hline & & & fadE8 \\
\hline & & & fadE20 \\
\hline & & & FadE12 \\
\hline & & & fadA \\
\hline & & & FadA3 \\
\hline & & & Rv0147 \\
\hline & & & accD4 \\
\hline & & & Rv3548c \\
\hline & & & kasB \\
\hline & & & Rv2228c \\
\hline & & & mutT1 \\
\hline & & & accD2 \\
\hline & & & echA7 \\
\hline & & & accD3 \\
\hline & & & fadE13 \\
\hline
\end{tabular}

intermediary metabolism and respiration. The exposure of $\Delta 0148$ to components inhibiting ETC complexes I and II [27] revealed that $\Delta 0148$ responds to changes in the electron transport system, thus predicting its role in cell homeostasis. $M$. tuberculosis adapts to various stress conditions to survive as a successful pathogen inside the host [28]. $\Delta 0148$ interestingly showed decreased growth in hydrogen peroxide, CHP, DTT and DMSO, which indicates its sensitivity to oxidative and nitrogen stress. Thus, in response to stress, the differential growth of
$\Delta 0148$ demonstrates that the gene plays an important role in the protective efficacy against oxidative and nitrogen stress [29].

Contradictory to previous findings, Rv0148 showed increased expression in MDR isolates [18]. In the present study, $\Delta 0148$ showed resistance to first-line streptomycin and ethambutol and second-line amikacin and kanamycin drugs and the result was correlated with its interaction towards drug-resistance genes. Interactome analysis in the study suggests that Rv0148 interacts with kanamycin resistance genes Rv3538, mutT1, fas, Rv0130, Rv3389 and $h t d x$. The EIS gene is reported earlier to be involved in causing drug resistance of $M$. tuberculosis [30]. Our analysis reveals that Rv0148 interacts with eis genes accA2, fas, kasA, fabD, KasB and accD3. Rv0148 does not display any direct interaction with amikacin and ethambutol genes; however, the interactomes of EIS and amikacin share common interacting genes such as Rv2417c, Rv2414c, Rv3055, Rv1312, Rv1571, Rv3605c, Rv3839, Rv0428c, Rv0495c and Rv2242. As these proteins are connected to each other indirectly on a larger interactome space, we assume that drug resistance in $\Delta 0148$ strain could be due to some disruption of the interactome network.

The major findings from the current study prove that $h t d y$ is also involved in drug resistance and the increased expression of $h t d y$ in $\Delta 0148$ predicts that Rv0148 altered the expression of interacting partners in M. tuberculosis. Interactome analysis using STRING database predicts that Rv0148 has a strong interaction with kanamycin, eis and amikacin resistance genes. Further, interactome analysis reveals that Rv0148 and Htdy are connected to EIS and the interacting proteins of the drugs analysed in this study. Thus, we assumed that the absence of Rv0148 affects the interactome that might bring a major expression difference in these proteins resulting in drug resistance towards respective drugs. An additional transcriptome profiling of these strains will further help in identifying a clear mechanism towards drug resistance. Further, studies like double knockout mutant of Rv0148 and Rv3389 will provide the detailed functional role of these genes.

\section{Conclusion}

To summarize, Rv0148 is a non-essential gene belonging to the oxidoreductase family in M. tuberculosis. In silico approach and protein interaction studies reveal that Rv0148 interacts with Htdy, which is a protein of the hydroxyl acyl family. Htdy in the presence of Rv0148 is quite stable and fold expression of the gene is optimal. In the absence of Rv0148, increased fold expression of $h t d y$ proves that these two genes are functionally interconnected and furthermore it is experimentally proved. In addition to these findings, Rv0148 not only interacts 

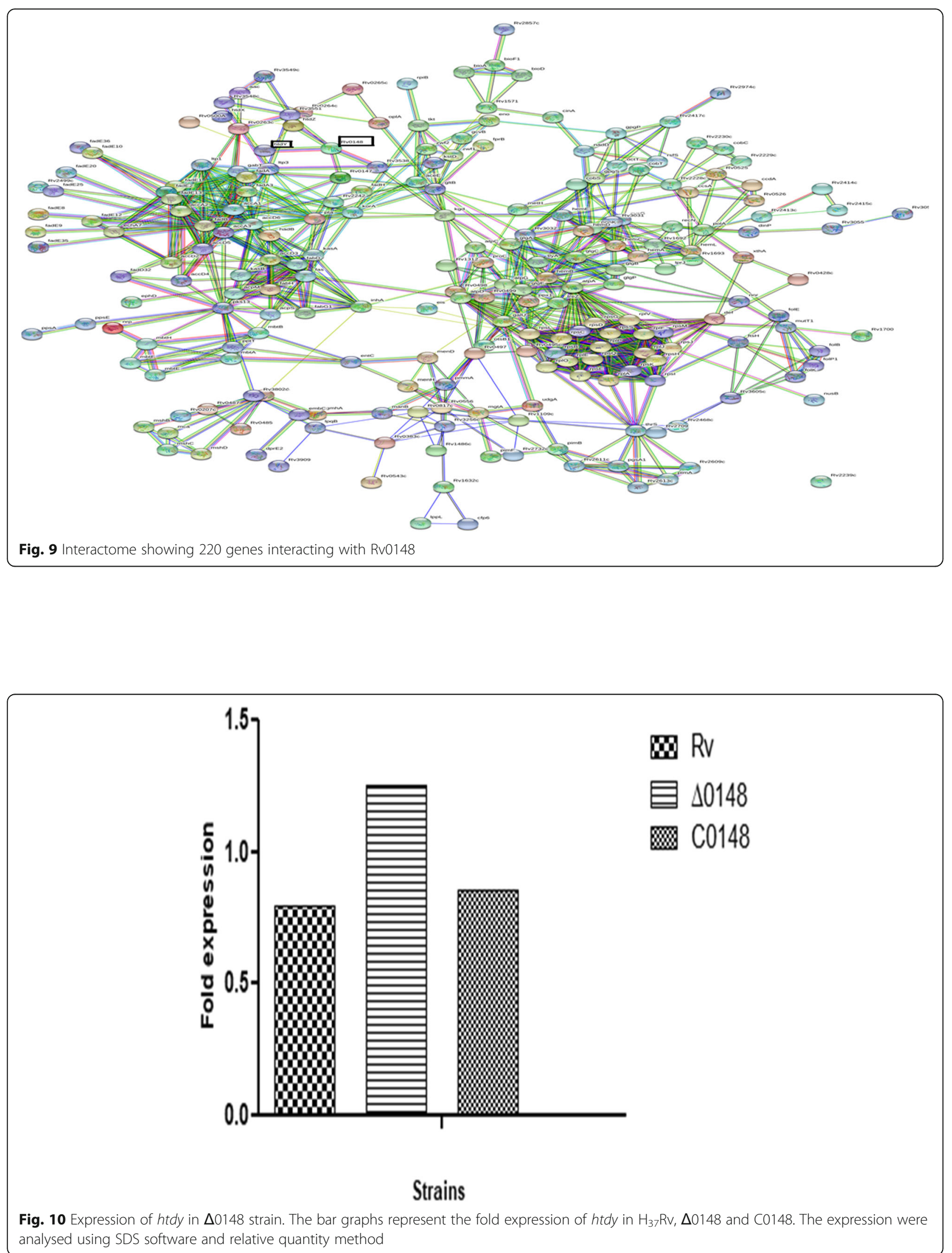
with $h t d y$, but also has a strong interactome network of 220 genes in $M$. tuberculosis with a high confidence of 0.7 . The absence of Rv0148 showed resistance to firstline drugs streptomycin and ethambutol and second-line drugs amikacin and kanamycin. Increased expression of pro-inflammatory cytokines suggests that $\Delta 0148$ might play a role in targeting the immune response. Our study suggests that Rv0148 plays a significant role in various functional aspects such as intermediatory metabolism, stress and homeostasis.

\section{Methods}

\section{Template selection and homology modelling}

A suitable template for Rv0148 was identified by searching in the PDB database using the default settings of BLAST program in February, 2017. The sequence of Rv0148 was searched against Pfam database to further identify available PDB structures having the same domain. The final template (PDB Id: $1 \mathrm{ZBQ}$ ) was chosen based on sequences having the highest sequence identity and domain coverage against Rv0148 sequence. The template 1ZBQ selected for modelling Rv0148, is the experimentally determined crystal structure of human 17-beta-hydroxysteroid dehydrogenase in complex with cofactor NAD. The template and the target sequence were aligned using the malign program in Modeller software [31]. Homology model of Rv0148 was constructed using Modeller and the quality of the model was further analysed using PROCHECK [32], ProSA-web [33] and verify 3D [34]. The model was also validated using root mean square deviation (RMSD).

\section{Molecular docking}

Docking was performed using NAD cofactor as the ligand with the predicted model of Rv0148 to understand its mode of interaction within the binding site. GOLD v5.2 (genetic optimization for ligand docking) is a widely used protein-ligand docking program [34]. GOLD uses a genetic algorithm methodology for protein-ligand docking that allows full ligand and partial protein flexibility. The homology model of Rv0148 protein was used as the receptor after the addition of hydrogen atoms before docking. The NAD ligand was corrected with Auto Edit Ligand option of GOLD program. Default genetic algorithm (GA) settings that ensure 100\% search efficiency were used for docking. A total of 20 poses of the docked molecule were generated. Early termination of the number of GA runs was allowed when the RMSDs of the top three GA solutions were within $1.5 \AA$. The best pose of the docked ligand was selected based on Goldscore.

\section{Protein-protein docking}

The interactions between Rv0148 and Htdy structures were docked using ClusPro [35]. The ClusPro algorithm uses fast fourier transform correlation, making it feasible to generate billions of docked conformations by simple scoring functions. ClusPro filters the docked confirmations with near-native structures, ranks them based on their clustering properties and finally refines a limited number of structures by energy minimization. The server outputs the top predicted complexes based on energy and cluster size.

\section{Bacterial strains and growth conditions}

E. coli strains DH5 $\alpha$ and BL21 (DE3) (Invitrogen, USA) were used for cloning and expression of recombinant proteins. E. coli cells were grown in Luria Bertani (LB) medium with constant shaking at $37^{\circ} \mathrm{C}$. M. smegmatis $\left(\mathrm{mc}^{2} 155\right)$ was grown in Middlebrook $7 \mathrm{H} 9$ broth (Difco, USA) with $0.2 \%$ glycerol and $0.05 \%$ Tween- 80 . The media was supplemented with $50 \mu \mathrm{g} / \mathrm{mL}$ ampicillin for E. coli whenever needed. $M$. tuberculosis was also grown in 7H9 broth with antibiotics carbenicillin $50 \mu \mathrm{g} \mathrm{mL}$, cyclohexamide $10 \mu \mathrm{gmL}$, kanamycin $25 \mu \mathrm{g} \mathrm{mL}$ and hygromycin $50 \mu \mathrm{g} \mathrm{mL}$, wherever required, along with OADC and Tween-80. Primers used in the study are listed in Table S2. The plasmids and strains constructed in the present study are mentioned in Table 3.

\section{Cloning and expression of Rv0148 and htdy}

M. tuberculosis genomic DNA was isolated using CTAB$\mathrm{NaCl}$ standard method [36]. Coding region of Rv0148 from $M$. tuberculosis was amplified by polymerase chain reaction (PCR) using gene-specific oligonucleotides. The PCR product of $h t d y$ was further cloned into pRSET-B harbouring $T 7$ promoter and Rv0148 in pGEX 4 T-1 vector harbouring tac promoter with Bam HI at $5^{\prime}$ and Xho I at $3^{\prime}$ end as restriction sites. The resultant clone was confirmed through restriction digestion and DNA sequencing. For recombinant protein expression, pGBRJ3 and pGBRJ2 clones were transformed into E. coli BL21 (DE3) cells and protein expression was induced with $0.5 \mathrm{mM}$ isopropyl $\beta$ D-1 thiogalactopyranoside (Invitrogen, USA). Induced cells were grown for $4 \mathrm{~h}$ at $37^{\circ} \mathrm{C}$ and harvested by centrifugation at $8000 \mathrm{rpm}$ for $10 \mathrm{~min}$. The cell pellet was resuspended in ice-cold lysis buffer G $(50 \mathrm{mM}$ Tris $\mathrm{pH} 8$, $300 \mathrm{mM} \mathrm{NaCl}, 20 \%$ glycerol, $0.5 \mathrm{mM}$ phenyl methyl sulphonyl fluoride and $10 \mathrm{mM}$ imidazole) along with protease inhibitor cocktail Sigma fast (SIGMA, USA) and sonicated on ice using ultrasonic homogenizer ( 5 cycles: $30 \mathrm{~s}$ pulse and $1 \mathrm{~min}$ interval). Finally, the lysate was centrifuged at $10,000 \mathrm{rpm}$ for $10 \mathrm{~min}$ at $4{ }^{\circ} \mathrm{C}$ to separate soluble and insoluble proteins.

\section{Purification of Rv0148 and Htdy}

The soluble lysate proteins were analysed on 12\% SDS gel for confirmation of recombinant proteins and protein lysis. Lysate was purified using affinity column (Bio$\mathrm{RAD}, \mathrm{CA}, \mathrm{USA}$ ) and $6 \mathrm{X}$ histidine-tagged protein was 
Table 3 Plasmids and bacterial strains constructed in the study

\begin{tabular}{|c|c|c|}
\hline Plasmid & Source of description & $\begin{array}{l}\text { Reference/ } \\
\text { origin }\end{array}$ \\
\hline $\begin{array}{l}\text { E. coli } \\
\text { DH5a }\end{array}$ & 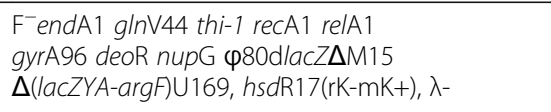 & Invitrogen \\
\hline $\begin{array}{l}\text { E. coli BL21 } \\
\text { (DE3) }\end{array}$ & $\begin{array}{l}\mathrm{F}^{-} \text {ompT gal dcm lon hsdS }{ }_{B}\left(r_{B}^{-} m_{B}^{-}\right) \\
\lambda(\text { DE3 [lacl lacUV5-T7 gene } 1 \text { ind1 sam7 nin5] }\end{array}$ & Invitrogen \\
\hline $\begin{array}{l}\text { M. } \\
\text { smegmatis } \\
m c^{2} 155\end{array}$ & Lab stock & \\
\hline pGEX 4 T-1 & $\operatorname{lacT}{ }^{q}, 4.9 \mathrm{~kb}, \mathrm{Amp}^{r}$, GST gene fusion vector & $\begin{array}{l}\text { GE } \\
\text { Healthcare }\end{array}$ \\
\hline pRSET-B & $\begin{array}{l}\text { lact } T^{q}, 2.8 \mathrm{~kb}, \mathrm{Amp}^{\mathrm{R}}, 6 \mathrm{xH} \text { His (N-term) gene } \\
\text { fusion vector }\end{array}$ & Invitrogen \\
\hline $\begin{array}{l}\text { p0004- Sac } \\
\text { B }\end{array}$ & $\begin{array}{l}\text { Suicide recombination delivery vector } \\
\text { carrying } \text { hyg }^{R} \text {-SacB for gene disruption, } \text { hyg }^{R}\end{array}$ & \\
\hline PhAE159 & $\begin{array}{l}\text { Conditionally replicating shuttle phasmid } \\
\text { vector }\end{array}$ & $\begin{array}{l}\text { William R } \\
\text { Jacobs Jr } \\
\text { (unpublished }\end{array}$ \\
\hline pMV261 & $\begin{array}{l}\text { E. coli mycobacterial shuttle vector, } \operatorname{Kan}^{\mathrm{R}} \text {, } \\
\text { hsp60 promoter }\end{array}$ & $\begin{array}{l}\text { Strover et al. } \\
\text { (1991) }\end{array}$ \\
\hline \multicolumn{3}{|c|}{ Constructs in this study } \\
\hline pGBRJ1 & $\begin{array}{l}\text { PRSET-B vector carrying the coding region } \\
\text { of Rv0148 gene from } M \text {. tuberculosis, Amp }\end{array}$ & This study \\
\hline pGBRJ2 & $\begin{array}{l}\text { pGEX } 4 \text { T-1 vector carrying the coding } \\
\text { region of Rv0148 gene from } M \text {. tuberculosis, } \\
\text { Amp }^{R}\end{array}$ & This study \\
\hline pGBRJ3 & $\begin{array}{l}\text { PRSET-B vector carrying the coding region } \\
\text { of Htdy gene from } M \text {. tuberculosis, Amp }{ }^{R}\end{array}$ & This study \\
\hline$\Delta 0148$ & $\begin{array}{l}\text { The deletion of Rv0148 gene from } M \text {. } \\
\text { tuberculosis }\end{array}$ & This study \\
\hline$C \Delta 0148$ & $\begin{array}{l}\text { pMV261 vector carrying the coding region } \\
\text { of Rv0148 gene from M. tuberculosis, Kan }{ }^{R} \\
\text { expressed in M. tuberculosis (complementation) }\end{array}$ & This study \\
\hline
\end{tabular}

bound to NI-NTA resin (Invitrogen, USA) and incubated at $12^{\circ} \mathrm{C}$ for $2 \mathrm{~h}$. The column was washed with 10 column volumes of wash buffer containing $40 \mathrm{mM}$ imidazole and was eluted with a buffer containing $200 \mathrm{mM}$ imidazole. Similarly, GST-tagged protein was bound to glutathione sepharose resin (GST, Takara, Japan) and eluted with $20 \mathrm{mM}$ reduced glutathione. The eluted fractions were then dialysed and analysed by SDS-PAGE and WB.

\section{Pull-down assay}

Pull-down assay was performed using poly-prep chromatography column (Bio-Rad, USA) with NI-NTA resin. Recombinant pGBRJ3 His lysate was incubated with NINTA resin for $2 \mathrm{~h}$ at $12{ }^{\circ} \mathrm{C}$ with gentle agitation. The column was washed with buffer containing $40 \mathrm{mM}$ imidazole and incubated overnight with pGBRJ2 GST lysate from E. coli BL21 (DE3) cells at $12^{\circ} \mathrm{C}$ with gentle agitation at $10 \mathrm{rpm}$ in an end-to-end shaker. Unbound proteins were removed by washing with 10 column volumes of buffer. The interacting proteins were eluted with buffer containing $200 \mathrm{mM}$ imidazole.

\section{Far western blot}

To recognize the Rv0148 interacting proteins, the fraction eluted in pull-down assay was separated on a 12\% SDSPAGE and transferred to Immobilon-P (PVDF) membrane. The membrane was denatured by incubation with varying concentrations $(6,3,1$ and $0.1 \mathrm{M})$ of guanidine$\mathrm{HCl}$ in $\mathrm{AC}$ buffer containing $5 \mathrm{M} \mathrm{NaCl}, 1 \mathrm{M}$ Tris $\mathrm{pH} 7.5$, $0.5 \mathrm{M}$ EDTA, $10 \%$ Tween-20, $2 \%$ skimmed milk powder, $10 \%$ glycerol and $1 \mathrm{M}$ dithiothreitol (DTT) for $30 \mathrm{~min}$ at room temperature followed by $5 \mathrm{~min}$ wash with phosphate buffer saline Tween 20 [37]. Then, the blot was completely renatured in $\mathrm{AC}$ buffer without guanidine- $\mathrm{HCl}$ and left overnight at $8{ }^{\circ} \mathrm{C}$. The membrane was then blocked with $5 \%$ skimmed milk and incubated with bait protein for $7-$ $8 \mathrm{~h}$ at $8{ }^{\circ} \mathrm{C}$ and further with 1:6000 anti-His monoclonal antibody and developed using enhanced chemiluminescent kit (Thermo Scientific, USA).

\section{Construction of allelic exchange substrate}

Gene disruption was carried out using Rv0148 left homology sequence (LHS) and right homology sequence (RHS) flanking regions carrying van911 as restriction site targeted for deletion and substitution. The gene was cloned onto either side of the selectable antibiotic cassette $[\gamma \delta(s a c B-h y g) \gamma \delta]$ to generate allelic exchange substrate for homologous recombination. Van911 restriction enzyme identifies a discontinuous palindrome interjected by five bases of sequence (CCAN_NNN^^NTGG) to achieve a four-fragment ligation.

\section{Construction of specialized transducing phages}

Shuttle phasmid phAE159 proliferates at $30^{\circ} \mathrm{C}$ and does not propagate in the infected mycobacterial cell at $37^{\circ} \mathrm{C}$. Shuttle phasmid phAE159 accommodates up to $10 \mathrm{~kb}$ of recombinant DNA into mycobacterial cells. The mycobacteriophage carrying AES disrupts a precise gene in mycobacteria through deletion-substitution. The AES with hygromycin resistance marker differs from the phasmid, and the use of in vitro lambda packaging extract (Epicentre, USA) helps in increasing the efficiency of transformation and also in the selection of phasmid DNA. Then the phasmid DNA was electroporated into M. smegmatis to produce specialized transducing phages (STPs) at permissive temperature of $30^{\circ} \mathrm{C}$. These phages were further propagated using MP buffer $(1 \mathrm{M}$ Tris $\mathrm{pH}$ $8,5 \mathrm{M} \mathrm{NaCl}, 1 \mathrm{M} \mathrm{MgCl}_{2}, 1 \mathrm{M} \mathrm{CaCl}_{2}$ ) to obtain high-titre allele-specific STPs.

\section{Specialized transduction}

Specialized transduction was performed at $37^{\circ} \mathrm{C}$ for the augmentation of STPs. In this temperature transfer of 
DNA to the host (mycobacterium) occurs with homologous recombination. The transduced $M$. tuberculosis cells were selected on hygromycin plate $(150 \mu \mathrm{g} / \mathrm{mL})$ after transduction. A minimum of five colonies appeared on the plate and was confirmed by PCR and Sanger sequencing using hyg as a forward primer and RHS as a reverse primer to confirm homologous recombination. For complementation of Rv0148, the gene was cloned into pMV261 vector harbouring $h s p 60$ promoter. The construct was then electroporated into the $\Delta 0148$ strain and colonies were screened on the 7H10 plate with antibiotic selection (kanamycin $20 \mathrm{mg} \mathrm{mL}$ ). Complementation was confirmed by PCR using Rv0148 primers and the complemented strain labelled as $C \Delta 0148$.

\section{In vitro growth kinetics of $\Delta 0148$}

To check whether the disruption of Rv0148 fetched any changes in the in vitro growth of $\mathrm{H}_{37} \mathrm{Rv}, \Delta 0148$ and C $\Delta 0148$ strains, log-phase cultures were grown in Middlebrook 7H9-OADC-Tween media and incubated at $37^{\circ} \mathrm{C}$ with $180 \mathrm{rpm}$ shaking. Aliquots of $100 \mu \mathrm{l}$ culture were taken at different time points and OD values were measured at $600 \mathrm{~nm}$ using spectrophotometer (Eppendorf) on days $0,3,6,9,12$ and 17. Survival of wild type, $\Delta 0148$ and $C \Delta 0148$ strains was analysed by plating the serial diluted broth cultures in 7H10 OADC agar without Tween-80. The plates were incubated for 3-4 weeks and the colony forming units were calculated.

\section{Colony morphology}

The colony morphology of the mutant was determined by comparing with complementary strain and wild type. The strains were grown in liquid 7H9 media to mid-log phase and $10 \mu \mathrm{l}$ of culture was inoculated to $7 \mathrm{H} 10$ agar plate supplemented with hygromycin. The plates were incubated at $37^{\circ} \mathrm{C}$ for $3-4$ weeks for colony formation.

\section{RNA extraction and qPCR}

Bacterial culture $100 \mathrm{~mL}$ was grown in $7 \mathrm{H} 9$ media to mid-log phase and the growth was arrested in ice and centrifuged at $4{ }^{\circ} \mathrm{C}$. The pellet was suspended in trizol (Invitrogen, USA). Cells were disrupted using $0.1 \mathrm{~mm}$ zirconium beads in a mini bead beater. The total RNA was extracted using the RNeasy purification kit (Qiagen, Germany) according to the manufacturer's protocol and quantified using ND-1000 Nanodrop spectrophotometer (Nanodrop Technologies). It was stored at $-80^{\circ} \mathrm{C}$. To determine the relative mRNA through $\mathrm{qPCR}$, the first strand cDNA was synthesized from $1 \mu \mathrm{g}$ of RNA using Maxima first strand cDNA synthesis kit (Thermo Scientific, USA). Quantitative qPCR primers for the Rv0148, $h t d y$ and 16S rRNA genes were designed (Table S2). qPCR was carried out using SYBR Green Master Mix (Thermo Scientific, USA) according to manufacturer's instructions using the Applied Biosystems 7300 realtime PCR system. Control reactions for each sample were carried out in the absence of reverse transcriptase to look over for DNA contamination. The amplification conditions for all reactions were 1 cycle of $50^{\circ} \mathrm{C}$ for 2 min, $95^{\circ} \mathrm{C}$ for $10 \mathrm{~min}$ followed by 40 cycles of $95^{\circ} \mathrm{C}$ for $15 \mathrm{~s}$ and $60^{\circ} \mathrm{C}$ for $1 \mathrm{~min}$. qPCR data analysis was carried out by relative quantification of Rv0148, htdy and $\mathrm{C} \Delta 0148$ gene expression using comparative calculated threshold (CT) method. For each qPCR run, the CT cycle was normalized to the internal control 16S rRNA gene amplified from the corresponding sample. Statistical analysis was carried out using SDS 2.4 software and relative quantity (RQ value) method. The data presented are averages of three independent experiments.

\section{Infection of knockout strain in THP-1 cell lines}

Intracellular viability of the knockout strain was determined using macrophage cell line infection studies. THP1 cells were grown in RPMI media with $10 \%$ fetal bovine serum. Cells were further grown to reach $1 \times 10^{6}$ cells, seeded onto 24-well plates and differentiated into macrophages using $50 \mathrm{mM}$ phorbol 12-myristate 13-acetate. Plates were incubated at $37{ }^{\circ} \mathrm{C}$ in the presence of $5 \% \mathrm{CO}_{2}$ incubator for 2 days, washed with RPMI medium and left overnight. Macrophages were then infected in triplicate with $\mathrm{H}_{37} \mathrm{Rv}, \Delta 0148$ and $\mathrm{C} \Delta 0148$ with multiplicity of infection of 1:10. Phagocytosis was allowed to take place for 4 $h$, after which the infected macrophages were incubated with RPMI containing streptomycin to eliminate extracellular bacteria. Further, the cell-free culture supernatants were collected on days $0,1,3,5$ and 7 post-infection and stored at $-80^{\circ} \mathrm{C}$ for cytokine analysis.

\section{Elisa}

The supernatants derived from THP-1 cell lines infected with $\mathrm{H}_{37} \mathrm{Rv}, \Delta 0148$ and $\mathrm{C} \Delta 0148$ at different intervals were evaluated for expression of cytokines IL-4, IL-6, IL10 , IL-1 $\beta$, TNF, IL-2, INF- $\gamma$, IL-12 (p40) and IL-12 (p70) by sandwich ELISA using BD ELISA kit (BD pharmingen, USA) according to manufacturer's protocol.

\section{Role of knockout mutant during oxidative stress}

To understand the role of oxidative and nitrogen stress in $\mathrm{H}_{37} \mathrm{Rv}, \Delta 0148$ and $\mathrm{C} \Delta 0148$, the strains were grown to mid-log phase in 7H9-OADC-T medium and exposed to various stress components such as electron transport chain (ETC) inhibitors, peroxides, sulphoxides, thiol stress with slight modification to the procedure by [27] and OD values were measured at $600 \mathrm{~nm}$ (OD600) for 4, 24 and $48 \mathrm{~h}$ time points. The graphs were plotted and significance was reported considering $P<0.01$ and $P<0.001$. 


\section{MGIT and drug susceptibility testing}

The $\mathrm{H}_{37} \mathrm{Rv}$ and knockout strains were grown on LJ solid media, 0.5 McFarland culture suspension was used for MGIT inoculation and drug susceptibility testing (DST) was performed for all the culture-positive MGIT tubes after 4 days. The growth control (GC) was prepared by diluting the cultures in the ratio of 1:100. The test cultures were prepared using saline in 1:5 dilution; $800 \mu \mathrm{L}$ of supplement was added to tubes according to manufacturer's protocol; $100 \mu \mathrm{L}$ streptomycin $1 \mu \mathrm{g} \mathrm{mL}$, isoniazid $0.1 \mu \mathrm{g} \mathrm{mL}$, rifampicin $1 \mu \mathrm{g} \mathrm{mL}$ and ethambutol $5 \mu \mathrm{g}$ $\mathrm{mL}$ (SIRE kit, BD). Kanamycin $2.5 \mu \mathrm{g} \mathrm{mL}$, ofloxacin $2 \mu \mathrm{g}$ $\mathrm{mL}$ and amikacin $1 \mu \mathrm{g} \mathrm{mL}$ was added to the respective tubes; and finally $500 \mu \mathrm{L}$ of culture was added to all the tubes and loaded in BACTEC MGIT 960. Tubes were recapped, mixed well and fixed into the BACTEC MGIT 960 using the antimicrobial susceptibility testing set entry protocol. BACTEC MGIT 960 instrument monitored susceptibility test until the growth unit of the GC reaches 400 [38].

\section{Interactome analysis to predict drug-resistance partners}

To predict the interacting genes involved in drug resistance, STITCH database was used and further analysed using a bioinformatics tool STRING.

\section{Expression of $h t d y$ in the presence and absence of Rv0148}

$\mathrm{H}_{37} \mathrm{Rv}$, mutant and complimentary strains were grown in 7 $\mathrm{H} 9$ media to log phase according to the growth conditions mentioned earlier and RNA was extracted. Individual and co-expression of $h t d y$ were analysed through qPCR in mutant and complementary strains and $\mathrm{H}_{37} \mathrm{Rv}$. The Ct and $R$ values were further considered for analysing the folds of gene expression.

\section{Statistical analysis}

The data represented all the three independent experiments carried out using replicates. Mean, standard error mean (SEM) and Two-way ANOVA was used to analyse the data obtained from in vitro kinetics, ELISA and oxidative stress assays $\left({ }^{* *} P<0.01\right.$ was said to be significant and ${ }^{* * *} P<0.001$ was said to be highly significant). Real time PCR data was analysed using SDS software and relative quantity method.

\section{Supplementary information}

Supplementary information accompanies this paper at https://doi.org/10. 1186/s12866-020-01763-1.

Additional file 1: Table S1. HMM analysis files showing 1270 significant sequences from Swissprot database.

Additional file 2: Table S2. List of primers used in this study. Table S3. Data showing $C T$ values for confirmation of gene knockout using real time PCR. Table S4. Data showing the CT values of $h$ tdy expression in gene knockout mutant.

Additional file 3: Figure S1. Restriction enzyme digestion of Rv0148 \&Rv3389 and cloning. (A) Confirmation of recombinant clones in pGEX4T-1 M: 1 kb marker, Lane 1 to 4; pGEX4T-1 as control with 4.9 kb size, Lane 5 to 8 recombinant clones, Lane 8 showing insert size $858 \mathrm{bp}$ (B) Confirmation of recombinant clones using restriction digestion in pRSET-B M; marker, Lane 1; Control pRSET-B correlating $2.8 \mathrm{~kb}$, Lane 2 to 6 showing recombinant clones with insert size $969 \mathrm{bp}$.

Additional file 4: Figure S2. Construction of knockout. (A) allelic exchange substrate construction M: 1 kb Marker, Lane 1: SacB digested with van911 showing four fragments $3.6 \mathrm{~kb}, 1.6 \mathrm{~kb}, 979 \mathrm{bp}, 567 \mathrm{bp}$, Lane 2\& 3: 0148 AES construct showing four fragments $3.6 \mathrm{~kb}, 1.6 \mathrm{~kb}, 837 \mathrm{RA}$, 605LA. (B) Packaging of AES with phAE159. M: $1 \mathrm{~kb}$ ladder, Lane 1: phAE159 digested with pac-I showing $50 \mathrm{~kb}$ and insert $3.8 \mathrm{~kb}$, Lane $2 \& 3$ clones without insert, Lane $4 \& 5$ clone digested with pac-I showing phAE159 $50 \mathrm{~kb}$ and 6.6 kb AES (C) Confirmation of knockout using PCR M: 1 kb ladder, Lane 1: Rv DNA amplified with right arm, Lane 2,4,5: knockout DNA amplified with hyg Forward primer and right arm reverse primer, Lane 6: Rv DNA not showed amplification with hyg \& reverse primer.

Additional file 5: Figure S3. Intersection of genes and role in drug resistance. Intersection of Rv0148, Htdy and EIS with the three drugs kanamycin, amikacin and streptomycin resulting in 57 interacting proteins.

\section{Abbreviations}

SDRs: Short-chain dehydrogenases/reductases; TB: Tuberculosis; $M$. tuberculosis: Mycobacterium tuberculosis; RNS: Reactive nitrogen species; ROS: Reactive oxygen species; AhpC: Alkylhydroperoxidase reductase; AhpE: Peroxiredoxin; Tpx: Thioredoxin reductase; MIC: Minimum inhibitory concentration; STPKs: Serine-threonine protein kinases; NAD: Nicotinamide adenine dinucleotide; PDB: Protein database; RT-PCR: Real-time Polymerase chain reaction; ELISA: Enzyme-linked immunosorbent assay;

MGIT: Mycobacteria growth indicator tube

Acknowledgements

Not applicable.

\section{Authors' contributions}

KP initiated and supervised the study. GB, SPT and KP designed the experiments. GB conducted the experiments. SH conducted the bioinformatics analysis. SB did the DST studies.GB, SH and KP has written the manuscript. All authors have read and approved the manuscript.

\section{Funding}

This work was supported by the ICMR-NIRT intramural research programme. GB awarded with PhD fellowship from the Department of Science and Technology INSPIRE programme. None of the funding bodies were involved in the design of the study, the collection, analysis, or interpretation of data, or in writing and communication of the manuscript.

\section{Availability of data and materials}

All data generated or analyzed during this study are included in this published article and its supplementary information files.

Ethics approval and consent to participate

No clinical samples were used in this study as this was an entirely in-vitro study using bacterial strains ethical review is not required.

Consent for publication

Not applicable.

\section{Competing interests}

The authors declare that they have no competing interests.

\section{Author details}

${ }^{1}$ Department of Immunology, ICMR-National Institute for Research in

Tuberculosis, \#1, Mayor Sathyamoorthy Road, Chetpet, Chennai 600031, India. 
${ }^{2}$ Department of Biological and Environmental Sciences, University of Gothenburg, Gothenburg, Sweden.

Received: 16 November 2019 Accepted: 23 March 2020 Published online: 15 April 2020

\section{References}

1. Kyu HH, Maddison ER, Henry NJ, Mumford JE, Mumford JE, Shields C. The global burden of tuberculosis: results from the global burden of disease study. Lancet Infect Dis. 2017;23:261-84.

2. WHO. Global Tuberculosis Report: World Health Organisation; 2018. https:// apps.who.int/iris/handle/10665/274453.

3. Boshoff HI, Barry CE 3rd. Tuberculosis - metabolism and respiration in the absence of growth. Nat Rev Microbiol. 2005;3(1):70-80.

4. Vergne I, Chua J, Singh SB, Deretic V. Cell biology of mycobacterium tuberculosis phagosome. Annu Rev Cell Dev Biol. 2004;20:367-94.

5. Uribe-Querol E, Rosales C. Control of phagocytosis by microbial pathogens. Front Immunol. 2017:8:1368.

6. Smith I. Mycobacterium tuberculosis pathogenesis and molecular determinants of virulence. Clin Microbiol Rev. 2003;16(3):463-96.

7. Kumar A, Farhana A, Guidry L, Saini V, Hondalus M, Steyn AJ. Redox homeostasis in mycobacteria: the key to tuberculosis control? Expert Rev Mol Med. 2011;13:e39.

8. Trivedi A, Singh N, Bhat SA, Gupta P, Kumar A. Redox biology of tuberculosis pathogenesis. Adv Microb Physiol. 2012;60:263-324.

9. Voskuil MI, Bartek IL, Visconti K, Schoolnik GK. The response of mycobacterium tuberculosis to reactive oxygen and nitrogen species. Front Microbiol. 2011:2:105.

10. MacMicking JD, North RJ, LaCourse R, Mudgett JS, Shah SK, Nathan CF. Identification of nitric oxide synthase as a protective locus against tuberculosis. Proc Natl Acad Sci U S A. 1997;94(10):5243-8.

11. Nambi S, Long JE, Mishra BB, Baker R, Murphy KC, Olive AJ, Nguyen HP, Shaffer SA. The Oxidative Stress Network of Mycobacterium tuberculosis Reveals Coordination between Radical Detoxification Systems. Cell Host Microbe. 2015;17(6):829-37.

12. Deretic V, Philipp W, Dhandayuthapani S, Mudd MH, Curcic R, Garbe T, Heym B, Via LE, Cole ST. Mycobacterium tuberculosis is a natural mutant with an inactivated oxidative-stress regulatory gene: implications for sensitivity to isoniazid. Mol Microbiol. 1995;17(5):889-900.

13. Edwards KM, Cynamon MH, Voladri RK, Hager CC, DeStefano MS, Tham KT Lakey DL, Bochan MR, Kernodle DS. Iron-cofactored superoxide dismutase inhibits host responses to Mycobacterium tuberculosis. Am J Respir Crit Care Med. 2001;164(12):2213-9.

14. Jaeger T, Budde H, Flohe L, Menge U, Singh M, Trujillo M, Radi R. Multiple thioredoxin-mediated routes to detoxify hydroperoxides in Mycobacterium tuberculosis. Arch Biochem Biophys. 2004;423(1):182-91.

15. Sherman DR, Mdluli K, Hickey MJ, Arain TM, Morris SL, Barry CE 3rd, Stover CK. Compensatory ahpC gene expression in isoniazid-resistant Mycobacterium tuberculosis. Science. 1996;272(5268):1641-3.

16. Sharma D, Kumar B, Lata M, Joshi B, Venkatesan K, Shukla S, Bisht D. Comparative proteomic analysis of aminoglycosides resistant and susceptible Mycobacterium tuberculosis clinical isolates for exploring potential drug targets. PLoS One. 2015;10(10):e0139414

17. Sharma D, Singh R, Deo N, Bisht D. Interactome analysis of Rv0148 to predict potential targets and their pathways linked to aminoglycosides drug resistance: an insilico approach. Microb Pathog. 2018:121:179-83.

18. Sharma D, Lata M, Faheem M, Khan AU, Joshi B, Venkatesan K, Shukla S, Bisht D: Cloning Expression and Correlation of Rv0148 to Amikacin \& Kanamycin Resistance. Curr Proteomics 2015;12:96-100.

19. Venkatesan A, Hassan S, Palaniyandi K, Narayanan S. In silico and experimental validation of protein-protein interactions between Pknl and Rv2159c from Mycobacterium tuberculosis. J Mol Graph Model. 2015;62: 283-93.

20. Venkatesan A, Palaniyandi K, Sharma D, Bisht D, Narayanan S. Functional characterization of Pknl-Rv2159c interaction in redox homeostasis of Mycobacterium tuberculosis. Front Microbiol. 2016;7:1654

21. Jain P, Hsu T, Arai M, Biermann K, Thaler DS, Nguyen A, Gonzalez PA, Tufariello JM, Kriakov J, Chen B, et al. Specialized transduction designed for precise high-throughput unmarked deletions in Mycobacterium tuberculosis. mBio. 2014;5(3):e01245-14.
22. Sassetti CM, Boyd DH, Rubin EJ. Genes required for mycobacterial growth defined by high density mutagenesis. Mol Microbiol. 2003;48(1):77-84

23. Russell-Goldman E, Xu J, Wang X, Chan J, Tufariello JM. A Mycobacterium tuberculosis Rpf double-knockout strain exhibits profound defects in reactivation from chronic tuberculosis and innate immunity phenotypes. Infect Immun. 2008;76(9):4269-81.

24. Cooper AM, Mayer-Barber KD, Sher A. Role of innate cytokines in mycobacterial infection. Mucosal Immunol. 2011;4(3):252-60.

25. Couper KN, Blount DG, Riley EM. IL-10: the master regulator of immunity to infection. J Immunol. 2008;180(9):5771-7.

26. Ana MP, Melo TMB, Teixeira M. New insights into type II NAD(P)H:Quinone Oxidoreductases; 2004

27. Bhat SA, lqbal IK, Kumar A. Imaging the NADH:NAD(+) homeostasis for understanding the metabolic response of Mycobacterium to physiologically relevant stresses. Front Cell Infect Microbiol. 2016;6:145.

28. Yano T, Li LS, Weinstein E, Teh JS, Rubin H. Steady-state kinetics and inhibitory action of antitubercular phenothiazines on mycobacterium tuberculosis type-II NADH-menaquinone oxidoreductase (NDH-2). J Biol Chem. 2006;281(17):11456-63.

29. Bulatovic VM, Wengenack NL, Uhl JR, Hall L, Roberts GD, Cockerill FR 3rd, Rusnak F. Oxidative stress increases susceptibility of Mycobacterium tuberculosis to isoniazid. Antimicrob Agents Chemother. 2002:46(9):2765-71.

30. Gikalo MB, Nosova EY, Krylova LY, Moroz AM. The role of eis mutations in the development of kanamycin resistance in Mycobacterium tuberculosis isolates from the Moscow region. J Antimicrob Chemother. 2012;67(9):2107-9.

31. Hatherley R, Brown DK, Glenister M, Tastan Bishop O. PRIMO: an interactive homology modeling pipeline. PLoS One. 2016;11(11):e0166698.

32. Laskowski RA, Jablonska J, Pravda L, Varekova RS, Thornton JM. PDBsum: structural summaries of PDB entries. Protein Sci. 2018;27(1):129-34.

33. Wiederstein M, Sippl MJ. ProSA-web: interactive web service for the recognition of errors in three-dimensional structures of proteins. Nucleic Acids Res. 2007;35(Web Server issue):W407-10

34. Cloete R, Kapp E, Joubert J, Christoffels A, Malan SF. Molecular modelling and simulation studies of the Mycobacterium tuberculosis multidrug efflux pump protein Rv1258c. PLoS One. 2018;13(11):e0207605.

35. Kozakov D, Hall DR, Xia B, Porter KA, Padhorny D, Yueh C, Beglov D, Vajda S. The ClusPro web server for protein-protein docking. Nat Protoc. 2017;12(2): 255-78.

36. Baess I. Isolation and purification of deoxyribonucleic acid from mycobacteria. Acta Pathol Microbiol Scand B: Microbiol Immunol. 1974; 82(6):780-4

37. Wu Y, Li Q, Chen XZ. Detecting protein-protein interactions by far western blotting. Nat Protoc. 2007;2(12):3278-84.

38. NIRT: NIRT standard operating protocols. 2010.

\section{Publisher's Note}

Springer Nature remains neutral with regard to jurisdictional claims in published maps and institutional affiliations.
Ready to submit your research? Choose BMC and benefit from:

- fast, convenient online submission

- thorough peer review by experienced researchers in your field

- rapid publication on acceptance

- support for research data, including large and complex data types

- gold Open Access which fosters wider collaboration and increased citations

- maximum visibility for your research: over $100 \mathrm{M}$ website views per year

At BMC, research is always in progress.

Learn more biomedcentral.com/submissions 